\title{
Modes of action, resistance and toxicity of insecticides targeting nicotinic acetylcholine receptors
}

\author{
Makoto Ihara $^{\mathrm{a}}$, Steven D. Buckingham ${ }^{\mathrm{b}}$, Kazuhiko Matsuda ${ }^{\mathrm{a}}$ and $*$ David B Sattelle $^{\mathrm{b}}$ \\ ${ }^{a}$ Department of Applied Biological Chemistry, Faculty of Agriculture, Kindai University, 3327-204 Nakamachi, \\ Nara 631-8505, Japan \\ ${ }^{b}$ Centre for Respiratory Biology, UCL Respiratory, Division of Medicine, University College London, Rayne Building, 5 \\ University Street, London WCIE 6JF, UK
}

\begin{abstract}
Nicotinic acetylcholine receptors (nAChRs) are members of the cys-loop superfamily of ligand-gated ion channels (cys-loop LGICs) and mediate fast cholinergic synaptic transmission in the nervous system of insects. The completion of many insect genome projects has greatly enhanced our understanding of the individual subunits that make up nAChR gene families from an insect genetic model organism (Drosophila melanogaster), crop pests, disease vectors and beneficial (pollinator) species. In addition to considerable insect nAChR subunit diversity, individual subunits can be subject to alternative splicing and RNA editing and these post-transcriptional modifications can add significantly to the diversity of nAChR receptor subtypes. The actions of insecticides targeting nAChRs, notably cartap, neonicotinoids, sulfoximines, flupyradifurone, spinosyns and triflumezopyrim are reviewed. Structural studies obtained using an acetylcholine binding protein (AChBP) co-crystallised with neonicotinoids have yielded important new insights into the requirements for neonicotinoid insecticide $-\mathrm{nAChR}$ interactions. The persistent application of insecticides to crop pests leads to the onset of resistance and several examples of resistance to insecticides targeting $\mathrm{nAChRs}$ have been documented. Understanding the molecular basis of resistance can inform our understanding of the mechanism of insecticide action. It also provides an important driver for the development of new chemistry, diagnostic tests for resistance and the adoption of application strategies designed to attenuate such problems. Finally, we consider toxicity issues relating to nAChR-active insecticides, with particular reference to beneficial insect species (pollinators) as well as mammalian and avian toxicity. This review is part of the special issue "Insecticide Mode of Action: From Insect to Mammalian Toxicity"
\end{abstract}

Keywords: nicotinic acetylcholine receptor, neonicotinoids, spinosyns, sulfoximines, butenolides, triflumezopyrim, insecticide, resistance, toxicity.

\section{INTRODUCTION}

Insect nicotinic acetylcholine receptors (nAChRs) are targets for several classes of insecticides [1,2]. The major family of insecticides targeting nAChRs are the neonicotinoids which have been deployed for 25 years and are still among the most important insecticides worldwide [3]. They are used in many applications, notably crop protection and animal health. Growing problems of resistance [4] pose a threat to their future and concerns regarding their possible adverse actions on pollinating insects [5] have led to restrictions on their use in Europe. The first commercial neonicotinoid, imidacloprid, quickly became the biggest selling insecticide worldwide [6]. Like nicotine, with which it shares some chemical similarities, imidacloprid activates nAChRs for which the natural ligand is the neurotransmitter acetylcholine (ACh). These receptors belong to a cys-loop superfamily of ligand gated ion channels (cys-loop LGICs), which in vertebrates also include receptors for $\gamma$-aminobutyric acid (GABA), glycine and 5-hydroxytryptamine (5-HT) [7] and in invertebrates also include receptors for GABA, 5-HT, ACh, L-glutamate, histamine, dopamine and tyramine [8].
Although neonicotinoids have dominated the insecticide market in recent years, they are far from the first nicotine-like molecules to be used to control insect pests. It may seem remarkable now but a century ago nicotine itself was used to control insect pests of plants [9]. It was not particularly effective, is extremely toxic and hence today is only of historical interest. Following observations by Japanese fishermen that crustaceans became paralysed when placed in the same containers as ragworms, nereistoxin was isolated from the marine annelid Lumbriconereis heteropoda and became the basis for several related synthetic compounds, most notably cartap [10, 11, 12]. Other nicotine-like compounds (nicotinoids) were identified as insecticide candidates including synthetic compounds containing a 3pyridylmethylamine group and a basic amino nitrogen atom [13] as well as molecules of plant origin such as charatoxins [14].

A fore-runner to the incredibly successful neonicotinoid class of chemistry was the compound developed by Shell, nithiazine, a nitromethylene compound. Nithiazine and related compounds were found to be active at insect nicotinic 
cholinergic synapses [15] and were subsequently shown to act on insect nAChRs [16]. However, these nitromethylenes displayed poor photostability which precluded their development as commercial insecticides. This work paved the way for the later discovery by Shinzo Kagabu and colleagues at Bayer of imidacloprid (1-(6-chloro-3-pyridylmethyl)-2nitroimino-imidazolidine) which showed many improved properties [17]. Introduced as an insecticide in 1991, by 1999 it was the world's number one insecticide based on sales. Since then spinosyns [18] and other insecticides, most recently triflumezopyrim [19], have been developed with several different modes action on nAChRs.
A

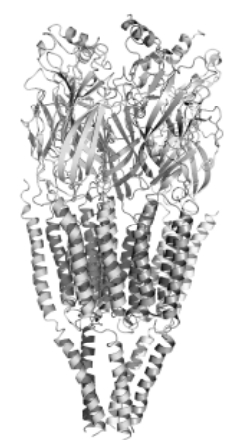

B

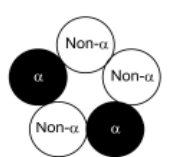

C

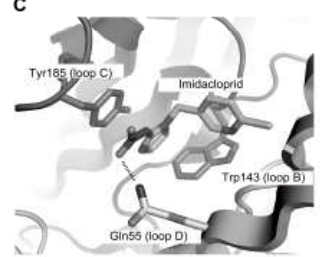

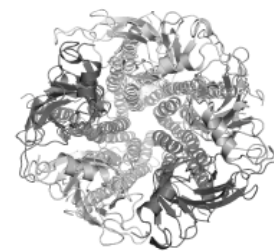
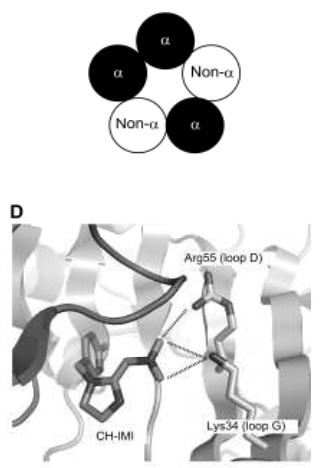

Figure 1 Three dimensional structures of the Torpedo nicotinic acetylcholine receptor (nAChR) and the acetylcholine binding protein (AChBP) help understand nAChR-neonicotinoid interactions. A, Side and top views of the Torpedo nAChR (PDB: 2BG9 [22]), are illustrated using the PyMOL software. B. Stoichiometry of $\alpha$ and non- $\alpha$ subunits in hetero-pentameric nAChRs. C. Interactions of imidacloprid with wild type Lymnaea stagnalis AChBP illustrated based on PDB: 2ZJU. The nitro group of imidacloprid forms a hydrogen bond with Gln55 in loop D. D. Interactions of nitromethylene analogue of imidacloprid (CH-IMI) with the Q55R mutant of the Lymnaea stagnalis AChBP illustrated based on PDB: 3WTM. The nitro group of CH-IMI interacts not only with Arg55 in loop D, but also with Lys34 in loop G.

\section{NICOTINIC ACETYLCHOLINE RECEPTORS} (nAChRs) OF INSECTS

2.1 Structure and function of insect $\mathrm{nAChRs}$
Acetylcholine is the primary afferent neurotransmitter in insects and the insect nervous system is richer in $\mathrm{nAChRs}$ than almost any other tissue other than the electric organ of the electric fish [2]. Insect nAChRs act as molecular switches which change conformation upon binding to the natural transmitter ACh, nicotine or related agonist compounds, allowing a net influx of cations into the cell. They are pentameric proteins and each of the 5 subunits has 4 transmembrane regions (TM1-4) with a long N-terminal extracellular domain containing the characteristic cys-loop motif. This consists of two disulphide bond-forming cysteines separated by 13 amino acid residues. The cys-loop has roles in receptor assembly [20] and the kinetics of ion channel gating [21]. The binding site for ACh and agonists is situated in the extracellular domain at the interface of two adjacent subunits and is formed by 6 distinct regions (loops A-F). The nAChR subunits possessing two adjacent cysteines in loop $\mathrm{C}$ which are critical for ACh binding are referred to as $\alpha$ subunits. Those subunits lacking these adjacent cysteines are designated non- $\alpha$. The 5 subunits that make up each nAChR molecule form a central cation pore; nAChRs can exist as homo-pentamers of $\alpha$ subunits or hertero-pentamers of either two kinds of $\alpha$ subunit or more commonly of various combinations of $\alpha$ and non- $\alpha$ subunits [22].

\subsection{Insect $\mathrm{nAChR}$ gene families}

Insect $\mathrm{nAChRs}$ mediate fast synaptic transmission in the nervous system and are targets for several classes of insecticidally-active molecules, most notably the neonicotinoids. The subunit composition of distinct subtypes of $\mathrm{nAChR}$ determines both functional and pharmacological properties of the receptor. Since nAChR families contain multiple subunit-encoding genes, this provides a molecular basis for the rich diversity of properties and pharmacology of nAChR subtypes. Comparative insect genomics has shown that nAChR gene families are relatively compact even in diverse insect species, when compared to their nematode and vertebrate counterparts. For example, the fruit fly (Drosophila melanogaster), the mosquito which serves as a malarial vector (Anopheles gambiae), the honey bee (Apis mellifera), the silk worm (Bombyx mori) and the red flour beetle (Tribolium castaneum), a stored product pest, possess 10-12 nAChR subunit encoding genes. This contrasts with humans and the nematode, Caenorhabditis elegans, which have 16 and at least 29 subunits respectively [22]. Although insect $\mathrm{nAChR}$ gene families are some of the smallest known, nAChR diversity is often greatly enhanced by alternative splicing and mRNA Ato-I editing. These post-transcriptional processes can potentially generate protein products which outnumber by many times the number of nAChR genes. Modifications generated in this way can result in species-specific subunit isoforms. Interestingly, each insect appears to possess at least one highly divergent $\mathrm{nAChR}$ subunit which may conceivably perform species-specific functions [22]. Subunit diversification that is species-specific may offer candidate targets for future insecticides designed to target insect pests while sparing beneficial insect species.

2.3 Insights from studies on an acetylcholine binding protein $(\mathrm{AChBP})$ 
Until recently, no high-resolution, crystal structure of an entire nAChR was available. However, a 4.0 Angstrom structure of the Torpedo electric organ nAChR [23] and the 2.7 Angstrom structure of an ACh binding protein (AChBP) from the pond snail Lymnaea stagnalis which shares common homology with the extracellular domain of the nAChR have been very instructive [24]. Of particular interest are recent studies in which AChBP (wild type and mutated to better mimic the insect $\mathrm{nAChR}$ ) has been co-crystallised with neonicotinoid insecticides (Fig. 1). Another recent development has been the successful crystallization of the human $\alpha 4 \beta 2$ brain $\mathrm{nAChR}$ at 3.9 Angstroms resolution [25].

In the wild type Lymnaea stagnalis AChBP-imidacloprid complex, the nitro group of imidacloprid forms a hydrogen bond with the amide group of Gln55 in loop D (Fig. 1), while the pyridine ring nitrogen forms hydrogen bonds via a water with the backbone of loop $\mathrm{E}$ and the $\mathrm{CH}_{2}-\mathrm{CH}_{2}$ bridge hydrogens contact with the aromatic ring of Trp143 in loop B by $\mathrm{CH}-\pi$ interactions and the imidazolidine ring stacks with the aromatic ring of Tyr185. Similar interactions were observed in the crystal structure of the wild type AChBP in complex with CH-IMI (Fig. 2), a nitromethylene analog of imidacloprid that of all neonicotinoids studied binds most strongly to the AChBP. However, in the case of clothianidin (Fig. 2), unlike imidacloprid, the nitro group does not make contact with Gln55 [26]. Thiacloprid does not stack with Tyr 185 and instead forms a hydrogen bond between its cyano group and the backbone of Tyr185 in loop C [27]. In Aplysia californica AChBP, the cyano group of thiacloprid interacts with the backbone of Tyr185 as in Lymnaea AChBP, which at first appears to deny the generality of AChBP interactions with neonicotinoids [28].

In insect non- $\alpha$ nAChR subunits such as the $\beta 1$ subunit of Drosophila, amino acids corresponding to the loop D Gln55 of Lymnaea stagnalis AChBP are arginine or lysine. Hence we mutated Gln55 to arginine to make AChBP resemble more closely insect non- $\alpha$ nAChR subunits. Such mutations resulted in hydrogen bond formation of the nitro group of clothianidin with Arg55. Interestingly, thiacloprid stacks with Tyr185 and interacts electrostatically with Arg55 in the Q55R mutant [26]. We also co-crystallised the wild type Lymnaea stagnalis AChBP and its Q55R mutant with desnitroimidacloprid, an imidacloprid metabolite lacking the nitro group. The guanidine tip of the metabolite is directed away from loop D, further supporting an important concept that the basic residues in loop D play a key role in defining the binding mode of neonicotinoids at the ligand-binding domain [26]. To summarize, a general concept has been established that neonicotinoids, nitro or cyano type, stack with the tyrosine residue in loop $\mathrm{C}$ and interact electrostatically with the basic residues in loop D.

Quite unexpectedly, crystallography studies showed that Lys34 in the $\beta 1$ strand, often referred to as "loop G", interacts with the nitro group of clothianidin and CH-IMI (Fig. 1) as well as with the cyano group of thiacloprid in the Q55R AChBP mutant [27]. In insect $\mathrm{nAChR} \alpha$-subunits, amino acids corresponding to the Lys 34 in the AChBP are preserved as basic residues. To confirm the role of such basic residues in loop $\mathrm{G}$ for the $\mathrm{nAChR}$-imidacloprid interactions, we mutated
Ser58 corresponding to Lys34 in AChBP to arginine in the $\alpha 7$ homomer-forming nAChR subunit and investigated the effects of the S58R mutation in the presence and absence of a mutation to arginine of Gln55 corresponding to Gln55 in the AChBP. The S58R mutant enhances the agonist actions of neonicotinoids, while reducing the actions of acetylcholine, (-)-nicotine and desnitro-imidacloprid. This is consistent with the finding that the basic residue in loop $\mathrm{G}$ is involved in the AChBP-neonicotinoid interactions at the orthosteric site. The basic residues in loop $\mathrm{G}$ interact via the complementary side or non- $\alpha$ side in the AChBP (Fig. 1), thus it appears that not only the $\alpha$-non- $\alpha$ interface, but also the $\alpha-\alpha$ interface contributes to the diverse and selective actions of neonicotinoids on insect nAChRs [27, 29].

\section{MODES OF ACTION OF INSECTICIDES TARGETING INSECT nAChRs}

\subsection{Nicotine and nicotinoids}

The powerful and rapid actions of nicotine on insects triggered the search for nicotine-like molecules as possible insecticides. Many plant-derived molecules were explored in this context.

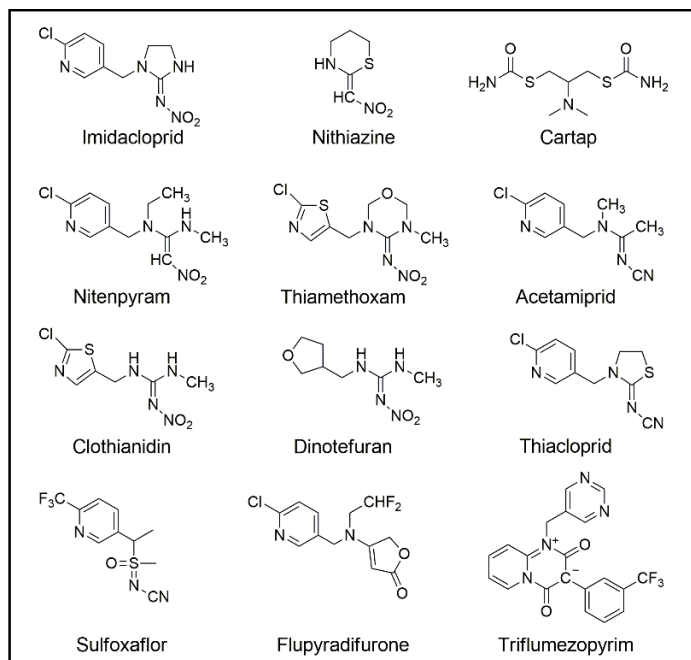

Figure 2 Chemical structures of commercial synthetic insecticides targeting insect nicotinic acetylcholine receptors (nAChRs).

One such example is provided by the charatoxins [14]. Other nicotine-like compounds (nicotinoids) were identified as insecticide candidates including synthetic compounds containing a 3-pyridylmethylamine group and a basic amino nitrogen atom [28]. Dihydronicotyrine and N,N di-substituted 3-pyridinylmethylamines were also generated but not taken forward as commercial insecticides [13].

\subsection{Cartap, an insecticide based on an invertebrate toxin,} nereistoxin

Cartap (Fig. 2) was developed by Takeda Chemical Industries. It is a derivative of nereistoxin which was isolated by Nitta in 1934 [10]. Nereistoxin was synthesized in 1965 by Hagiwara and colleagues [11]. A variety of nereistoxin derivatives were 
prepared and cartap was an important commercial product. Sattelle and colleagues described the detailed actions of nereistoxin at the nAChRs of the cercal afferent-giant fibre cholinergic synapse in the terminal abdominal ganglion of the cockroach Periplaneta americana [12]. Bensultap and monosultap are also nereistoxin-derived products.

\subsection{Nithiazine, a Neonicotinoid prototype}

Nithiazine (Fig. 2) is a nitromethylene heterocycle and its actions were reported on the cholinergic cercal afferent-giant fibre synapses in the cockroach terminal abdominal ganglion. The effects were biphasic; an initial increase in the frequency of spontaneous giant fibre discharges was followed by the development of a complete block of synaptic transmission [15]. Nithiazine and related compounds did not inhibit insect acetylcholinesterase. It was concluded that the site of action was postsynaptic, and likely involved an action on postsynaptic nAChRs [15]. Subsequent studies using an insect identified cockroach motor neuron and radioligand binding to cockroach CNS membranes with ${ }^{125}$ I- $\alpha$-bungarotoxin demonstrated agonist actions on insect nAChRs [16]. Although nithiazine itself was not commercialised, adding the 1-chloro-3-pyridyl moiety and replacing the nitromethylene by a nitroimine group to enhance efficacy and photostability led to the introduction of imidacloprid.

\subsection{Imidacloprid and the Neonicotinoid family of insecticides}

Imidacloprid (Fig. 2) was the first neonicotinoid to be commercialised. Introduced in 1991, imidacloprid became the world's biggest selling insecticide by the end of that decade [4]. Imidacloprid acts at the orthosteric site on insect nAChRs. Its agonist actions activate the cation permeable ion channel of the receptor [30]. In pentameric $n A C h R$ receptors consisting of $2 \mathrm{x} \alpha$ and $3 \mathrm{x}$ non- $\alpha$ subunits, the $6 \mathrm{ACh}$ binding site loops (loops A, B and C on the $\alpha$ subunit and loops D, E and $\mathrm{F}$ on the non- $\alpha$ subunit) make up the neurotransmitter (orthosteric) binding site, which is located at the $\alpha /$ non- $\alpha$ subunit interfaces. Important roles for loops B C D E and F in interactions with imidacloprid have been reported [25]. Recently, an additional site (loop $\mathrm{G}$ ) on the $\beta 1$ strand has been identified [29]. Also, when the $\alpha /$ non- $\alpha$ subunit ratio is $3 / 2$, another binding site is generated at the interface of two adjacent $\alpha$ subunits [29].

Other neonicotinoids include acetamiprid, clothianidin, nitenpyram, dinotefuran, thiacloprid and thiamethoxam (Fig. 2). When compared to organophosphate and carbamate insecticides, neonicotinoids are found to be less toxic to birds and mammals. When comparing their actions at their molecular target, insect nAChRs appear more sensitive to neonicotinoids than most of their vertebrate nAChR counterparts. Some breakdown products are however toxic. Detailed studies of neonicotinoid interactions with native and recombinant insect nAChRs reveal a variety of complex interactions with nAChRs (Table 1). Partial agonists, full agonists and superagonists have all been reported [31, 32, 33, 34]. For example, imidacloprid is a partial agonist, while clothianidin shows a higher efficacy than imidacloprid on native and recombinant fruit fly (Drosophila melanogaster) D $\alpha 2 /$ chicken (Gallus gallus) $\beta 2$ hybrid nAChRs (Table 1). Interestingly a nitromethylene analog of clothiandin was a super agonist on native Drosophila neurons which is due to increased open probability of the highest conductance state of the nAChRs expressed in the neurons [31]. In the dorsal

unpaired neurons in the thoracic ganglia of the cockroach, Periplaneta americana, desensitizing (D) and nondesensitizing (ND) nAChRs are present. On the D type of nAChRs imidacloprid acts as an agonist, whereas it is an antagonist on the ND class of nAChRs [35]. Alkylenetethered imidacloprid derivates were tested on native cockroach neurons to show that they were also antagonists [34]. The diverse actions of neonicotinoids on various insect nAChRs are summarized in Table 1.

\subsection{Sulfoxaflor, a sulfoximine insecticide}

Sulfoxaflor (Fig. 2) belongs to the sulfoximine class of insecticides which are often used to target sap-feeding insects. Sulfoxaflor binds to the orthosteric (agonist) site on insect nAChRs competing directly with the neurotransmitter ACh. Binding causes uncontrolled neuronal firing resulting in muscle tremors followed by paralysis and death [36]. Thus sulfoximines bind to the orthosteric binding site and show agonist [37] and rapidly desensitizing [38] actions.

\subsection{Flupyradifurone, a butenolide insecticide}

Flupyradifurone (Fig. 2) displaces $\left[{ }^{3} \mathrm{H}\right]$-imidacloprid binding to housefly Musca domestica membranes enriched in nAChRs. Whole-cell current responses were recorded following application of flupyradifurone and ACh to neurons isolated from the nervous system of the lepidopteran pest, the army fall worm Spodoptera frugiperda. The results point to activation of insect $\mathrm{nAChRs}$ and action as a partial agonist. The flupyradifurone dose-response curve revealed a Hill coefficient close to one suggesting a single binding site [39].

\subsection{Spinosyns}

Spinosad is an insecticide based on chemical compounds present in the bacterium Saccharopolyspora spinosa [17]. Fascinatingly, S. spinosa was isolated from soil collected in the Virgin Islands. Spinosad is derived from a family of natural products obtained by fermentation of S. spinosa. Spinosyns occur in over 20 natural forms, and over 200

synthetic forms (spinosoids) have been produced. Spinosad contains a mix of two spinosoids, spinosyn A, the major component (Fig. 3), and spinosyn D (the minor component), in a roughly $17: 3$ ratio.

Spinosyns contain a tetracyclic ring system attached to an amino sugar (D-forosamine) and a neutral sugar (tri-Omethyl-L-rhamnose). The spinosyns exhibit a novel mode of 
action on insect nAChRs. They target binding sites on nAChRs that are distinct from those at which other insecticides bind. Watson et al [40] and Perry et al [41] have provided strong evidence that the D. melanogaster D $\alpha 6$ subunit [42] is targeted by spinosad. There are several examples of insect pest species where mutations in the $\alpha 6$ nAChR subunit are associated with high levels of resistance to spinosad. One recent example is a mutation G275E in the $\alpha 6$ nAChR subunit of the tomato leaf miner Tuta absoluta [43].

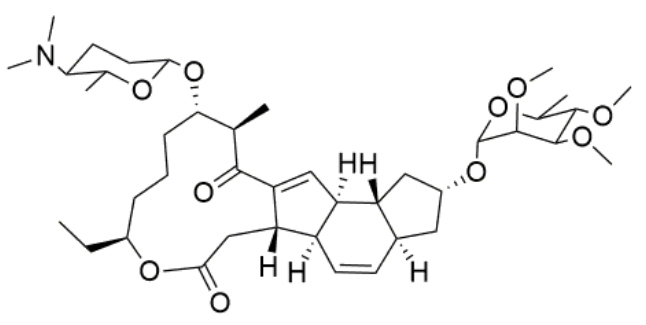

\section{Spinosyn A}

Figure 3 Chemical structure of spinosyn A, a component of a commercial insecticide (spinosad) of natural product origin targeting insect nAChRs.

\subsection{Triflumezopyrim}

Triflumezopyrim (Fig. 2) is a recently commercialized molecule from DuPont Crop Protection. It belongs to a new class of mesoionic insecticides [19]. It displaced ${ }^{3} \mathrm{H}-$ imidacloprid binding from membranes of the aphid Myzus persicae. The competitive nature of its action points to an interaction with the orthosteric site on nAChRs. Voltageclamp electrophysiology on cockroach (Periplaneta americana) neurons showed that triflumezopyrim suppressed $\mathrm{nAChR}$ currents. Similar actions were observed on hybrid recombinant receptors composed of D. melanogaster $\mathrm{D} \alpha 2$ and chicken $\beta 2$ subunits. The rapid, prolonged nAChR blocking actions seen in $P$. americana neurons, are quite distinct from the actions of other insecticides targeting insect nAChRs. Triflumezopyrim acts by inhibition of the orthosteric nAChR binding site. It is the first commercial insecticide with this type of action and it provides excellent control of hoppers, including the brown planthopper, Nilaparvata lugens, for which strong resistance to imidacloprid has been reported [44].

\section{RESISTANCE TO INSECTICIDES TARGETING INSECT nAChRs}

Development of resistance is a major problem for all insecticides [36] and is perhaps one of the best examples of natural selection in action. Discussion here is confined to neonicotinoid resistance because of its high significance. Both target-site [44, 45] and metabolic [4] mechanisms conferring resistance have been reported.
In most cases neonicotinoid resistance results from metabolic changes. It involves the enhanced expression of one or more cytochrome P450s which are often detected in resistant strains. However a target site mutation causal for resistance was found in field populations of peach aphid Myzus persicae. Bass et al [45] reported that $\left[{ }^{3} \mathrm{H}\right]$-imidacloprid affinity for the membrane fraction was reduced by an R81T mutation of the $\mathrm{nAChR} \beta 1$ subunit. Interestingly, we earlier predicted that an important R81T mutation affecting neonicotinoid sensitivity was possible in loop D since the ACh concentration-response curve was unaffected by the $\mathrm{T}$ to $\mathrm{R}$ mutation, whereas the action of imidacloprid was affected [46].

In spite of the current scale of resistance, neonicotinoids continue to play an important role in many pest control programmes worldwide. Resistance management strategies, whereby insecticides with different modes of action are either co-applied or used in turn will be of crucial importance in preventing resistance becoming more widespread.

It is also interesting to note that mutations in the nAChR $\alpha 6$ subunit (e.g. G275E in Tuta absoluta) can confer resistance to spinosad [43]. Enhanced knowledge of such target site mutations will add to our understanding of the particular subunits targeted by the various insecticides acting on insect nAChRs.

\section{TOXICITY}

In this section we focus on toxicity issues in relation to neonicotinoids as they are the most widely used insecticides targeting nAChRs worldwide. Although incredibly successful and playing a key role in global food production, neonicotinoids have come under increasing scrutiny over their potential environmental impact. For example, their deployment has been linked to adverse ecological effects, including the decline of pollinating insects and the decline in bird populations as a result of reduced insect populations. In 2013, the European Union (EU) and along with some non-EU countries restricted the use of certain neonicotinoid insecticides.

\subsection{Mammalian and avian toxicity}

Neonicotinoids have been very successful since their introduction in 1991. They exhibit high affinity for insect nAChRs, lower affinity for many mammalian nAChRs and also show relatively low mammalian and bird toxicity [17]. Neonicotinoids are deployed as sprays; they can be applied as drenches or in granular form. They are sometimes introduced into water supplies used for irrigation or even injected into trees. Their most common application is as a seed treatment. In this case the insecticide is taken up systemically by the crop plant. This is a convenient and cost-effective way to apply neonicotinoids and has been widely used. This feature, as well as the development of resistance to other classes of insecticide by many insect pests, and the phasing out of earlier generations of insect control chemicals, has led to neonicotinoids capturing almost one fifth of the global 
insecticide market. Although vertebrates are less susceptible than arthropods to neonicotinoids, consumption of neonicotinoid dressed seeds could present risks to birds [47] and humans [48].

\subsection{Environmental concerns including risks to beneficial insects}

One perceived advantage of neonicotinoid insecticides is that they can control a broad-spectrum of insect pests. This offers advantages to arable farmers and horticulturalists. However, the seed-dressing (prophylactic) application of broadspectrum pesticides is at odds with the long-established principles of integrated pest management and this presents environmental concerns with respect to long-term repeat applications of these compounds [49].

The neonicotinoid insecticides can persist in the soil and ultimately find their way into watercourses. Also since their actions are systemic and designed to target sucking insect pests, they reach the nectar and the pollen of crop species and the wild flowers at the borders of treated fields. As a result the levels of neonicotinoids to which pollinators are exposed may reach $\mathrm{LC}_{50}$ values, the concentration that kills $50 \%$ of individuals. It has been shown that neonicotinoid concentrations in the nectar and pollen of crops can reach levels that affect colony reproduction in bumblebees [50].

More research is needed to explore the impact of neonicotinoids on a range of non-target invertebrates, notably pollinators. The evidence we have suggests that neonicotinoids with their broad-spectrum insecticide actions are likely to have adverse effects on a range of non-target invertebrates, not only pollinators but also possibly soil and water dwelling invertebrates [50]

\section{CONCLUSION}

Insecticides targeting nAChRs include an example of an insect control chemical developed from a natural invertebrate toxin. Toxins of plant origin have also been explored for their potential as insecticides and a toxin of bacterial origin has proved to be a very successful insecticide. To date, the most commercially successful insecticides targeting nAChRs have been the neonicotinoids. However, there are concerns regarding possible threats to insect pollinators and to the health of the soil which relies strongly on invertebrates for nutrient cycling and preserving soil structure. It will be important to identify key gaps in current knowledge in order to evaluate these threats and the challenges they present. A key issue is whether or not the current methods of neonicotinoid deployment provide the best balance between delivering adequate food production and maintaining biodiversity.

\section{CONFLICT OF INTEREST}

\begin{tabular}{|c|c|c|c|}
\hline Neonicotinid & Actions & $\begin{array}{l}\text { Native / } \\
\text { Recombinant } \\
\text { nAChRs }\end{array}$ & Refs \\
\hline Imidacloprid & $\begin{array}{l}\text { Antagonist } \\
\text { Potentiating } \\
\text { action }\end{array}$ & 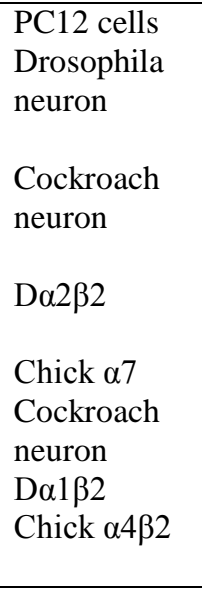 & $\begin{array}{l}{[51]} \\
{[31]} \\
{[35,52]} \\
{[53]} \\
{[32]} \\
{[32]} \\
{[35,32,} \\
54,55]\end{array}$ \\
\hline Acetamiprid & Partial agonist & $\begin{array}{l}\text { Cockroach } \\
\text { neuron }\end{array}$ & [53] \\
\hline Clothianidin & $\begin{array}{l}\text { Partial agonist } \\
\text { Full agonist / } \\
\text { Super agonist }\end{array}$ & 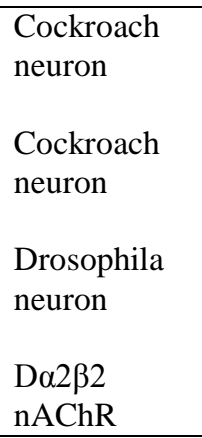 & $\begin{array}{l}{[52]} \\
{[53]} \\
{[31]} \\
{[56]}\end{array}$ \\
\hline P-CH-CTD & Super agonist & $\begin{array}{l}\text { Drosophila } \\
\text { neuron } \\
\text { D } \alpha 2 \beta 2 \\
\text { nAChR }\end{array}$ & $\begin{array}{l}{[31]} \\
{[56]}\end{array}$ \\
\hline Dinotefuran & $\begin{array}{l}\text { Partial agonist } \\
\text { Super agonist }\end{array}$ & $\begin{array}{l}\text { Cockroach } \\
\text { neuron } \\
\text { D } \alpha 2 \beta 2 \\
\text { nAChR }\end{array}$ & $\begin{array}{l}{[53]} \\
{[57]}\end{array}$ \\
\hline Nitenpyram & $\begin{array}{l}\text { Full agonist } \\
\text { Partial agonist }\end{array}$ & $\begin{array}{l}\text { Cockroach } \\
\text { neuron } \\
\text { D } \alpha 1 \beta 2 \\
\text { D } \alpha 2 \beta 2 \\
\alpha 7 \text { nAChRs }\end{array}$ & $\begin{array}{l}53] \\
{[32]}\end{array}$ \\
\hline Thiacloprid & Antagonist & Chick $\alpha 4 \beta 2$ & {$[55]$} \\
\hline CH-IMI & $\begin{array}{l}\text { Full agonist } \\
\text { Partial agonist }\end{array}$ & $\begin{array}{l}\mathrm{D} \alpha 2 \beta 2 \\
\alpha 7 \\
\mathrm{D} \alpha 1 \beta 2\end{array}$ & $\begin{array}{l}{[32]} \\
{[32]} \\
\end{array}$ \\
\hline
\end{tabular}

DBS and SDB are supported by The Division of Medicine, University College London, UK and DBS is Chief Scientific Officer of CeBioscience Ltd. KM and MI are supported by 
Kindai University and acknowledge support of grant from the Ministry of Agriculture, Forestry, and Fisheries of Japan (Genomics-based Technology for Agricultural Improvement, PRM-3002). MI was supported by JSPS KAKENHI Grant Number 16K21507.

\section{ACKNOWLEDGEMENTS}

All authors are indebted to their colleagues in their laboratories at University College London, UK and Kindai University, Nara, Japan.

\section{REFERENCES}

[1] Gepner, J.I.; Hall, L.M.; Sattelle, D.B. Insect acetylcholine receptors as a site of insecticide action. Nature, 1978 276, 188-190.

[2] Sattelle, D.B. Acetylcholine receptors of insects. Adv. Insect Physiol., $198015,215-315$

[3] Matsuda, K.; Buckingham, S.D.; Kleier, D.; Rauh, J.J.; Grauso, M.; Sattelle, D.B. Neonicotinoids: insecticides acting on insect nicotinic acetylcholine receptors. Trends Pharmacol. Sci., 2001 22, 573-580.

[4] Nauen, R.; Denholm, I. Resistance of insect pests to neonicotinoid insecticides: current status and future prospects. Arch. Insect Biochem. Physiol., 2005 58, 200-215.

[5] Henry, M.; Cerrutti, N.; Aupinel, P.; Decourtye, A.; Gayrard, M.; Odoux, J-F.; Pissard, A.; Ruger, C.; Bretagnolle, V. (2015) Reconciling laboratory and field assessments of neonicotinoid toxicity to honeybees. Proc. R. Soc. Lond. B., 2015 282, 20152110

[6] Raymond-Delpech, V.; Matsuda, K.; Sattelle, B.M.; Rauh, J.J.; Sattelle, D.B. Ion channels: molecular targets of neuroactive insecticides. Invert Neurosci., 2005 5,119-133.

[7] Barnard, E.A.; Darlison, M.G.; Harvey, R.; Marshall, J.; Moss, S.J.; Sattelle, D.B.; Smart, T.G.; Vrenghendil, E. Cloned genes for ligandoperated ion channels and their expression. Adv. Second Messenger Phosphoprotein Res., 1990 24, 20-29.

[8] Dent, J.A. The evolution of pentameric ligand-gated ion channels. Adv Exp. Med. Biol., 2010 683, 11-23.

[9] Yamamoto, I. In: Advances in Pest Control Research; Metcalf, R.L. Ed.; Wiley, New York, 1965; Vol. 6, pp. 231-260

[10] Nitta, S. Uber nereistoxin einen giften Bestandteil von Lumbriconereis heteropoda Marenz (Eunicidae). Yakagaku Zasshi, 1934 54, 648652.

[11] Hagiwara, H.; Numata, M.; Konishi, K.; Oka, Y. Synthesis of nereistoxin and related compounds I. Chem. Pharm. Bull. (Tokyo), 1965 13, 253260.

[12] Sattelle, D.B; Harrow, I.D; David, J.A; Pelhate, M. Callec, J.J. Gepner, J.I.; Hall, L.M. Nereistoxin: actions on an acetylcholine receptor/ion channel complex in the central nervous system of an insect Periplaneta americana (L.). J. exp. Biol., 1985 118, 37-52.

[13] Tomizawa, M.; Zhang, N.; Durkin, K.A.; Olmstead, M.M.; Casida, J.E. The neonicotinoid electronegative pharmacophore plays the crucial role in the high affinity and selectivity for the drosophila nicotinic receptor: an anomaly for the cation-pi interaction model. Biochemistry, $\mathbf{2 0 0 3} 42,7819-7827$

[14] Sherby, M.; Eldefrawi, A.T.; David, J.A.; Sattelle, D.B.; Eldefrawi, M.E. Interactions of charatoxins and nereistoxin with the nicotinic acetylcholine receptors of insect CNS and Torpedo electric organ. Arch. Insect Biochem. Phvsiol., 1986 3, 431-445.

[15] Schroeder, M.E.; Flattum, R.F. (1984). The mode of action and neurotoxic properties of the nitromethvlene heterocycle insecticides. Pestic. Biochem. Physiol., 1984 22, 148-160.

[16] Sattelle, D.B.; Buckingham, S.D.; Wafford, K.A.; Sherby, S.M.; Bakry, N.M.; Eldefrawi, A.T.; Eldefrawi, M.E.; May, T.E. Actions of the insecticide 2(nitromethylene) tetrahydro-1, 3-thiazine on insect and vertebrate nicotinic acetylcholine receptors. Proc. R. Soc. Lond. B., $1989237,501-514$

[17] Kagabu, S. Chloronicotinyl insecticides - discovery, application and future perspective. Rev. Toxicol., 1997 1, 75-129.

[18] Salgado, V.L.; Sheets, J.J.; Watson, G.B. Studies on the mode of action of spinosad: the internal effective concentration and concentrationdependence of neuronal excitation. Pestic. Biochem. Physiol., 1998 60, 103-110.

[19] Cordova, D.; Benner, E.A.; Schroeder, M.E.; Holvoke, C.W. Jr.; Zhang, W.; Pahutski, T.F.; Leighty, R.M.; Vincent, D.R.; Hamm, J.C. Mode of action of triflumezopyrim: a novel mesoionic insecticide which inhibits the nicotinic acetylcholine receptor. Insect Biochem. Mol. Biol., 2016 74, 32-41.

[20] Green, W.N.; Wanamaker, C.P. The role of the cysteine loop in acetylcholine receptor assembly. J. Biol. Chem., 1997 272, 2094520953

[21] Grutter, T.; de Carvalho, L.P.; Dufresne, V.; Taly, A.; Edelstein, S.J.; Changeux, J.P. Molecular tuning of fast gating in in pentameric ligand-gated ion channels. Proc Natl Acad Sci USA 2005102 $18207-18212$

[22] Jones, A.K.; Sattelle, D.B. Diversity of insect nicotinic acetylcholine receptor subunits. Adv. Exp. Med Biol., 2010 683, 25-43.

[23] Unwin, N. Refined structure of the nicotinic acetylcholine receptor at 4A resolution. J. Mol. Biol., 2005 346, 967-989.

[24] Breci, K.; van Diik, W.J.; Klassen, R.V. Schuurmans, M.; van Der Oost, J.; Smit, A.B.; Sixma, T.K. Crystal structure of an ACh binding protein reveals the ligand-binding domain of nicotinic receptors Nature, 2001 411, 269-276.

[25] Morales-Perez, C.L.; Noviello, C.M.; Hibbs, R.E. X-ray structure of the human $\alpha 4 \beta 2$ nicotinic receptor. Nature 538, 411-415.

[26] Ihara, M.; Okajima, T.; Yamashita, A.; Oda, T.; Hirata, K.; Nishiwaki, H.; Morimoto, T.; Akamatsu, M.; Ashikawa, Y.; Kuroda, S.; Mega, R.; Kuramitsu, S.; Sattelle, D.B.; Matsuda. K. Crystal structures of Lymnaea stagnalis AChBP in complex with neonicotinoid insecticides imidacloprid and clothianidin. Invert. Neurosci., 20088 , $71-81$.

[27] Ihara, M.; Okajima, T.; Yamashita, A.; Oda, T.; Asano, T.; Matsui, M.; Sattelle, D.B.; Matsuda, K. Studies on an acetylcholine binding protein identify a basic residue in loop $\mathrm{G}$ on the $\beta 1$ strand as a new structural determinant of neonicotinoid actions. Mol. Pharmacol. $201486,736-46$

[28] Talley, T.T.; Harel, M.; Hibbs, R.E.; Radic, Z.; Tomizawa, M.; Casida, J.E.; Taylor, P. Atomic interactions of neonicotinoid agonists with AChBP: molecular recognition of the distinctive electronegative pharmacophore. Proc. Natl. Acad. Sci. USA., 2008 $105,7606-7011$.

[29] Ihara, M.; Sattelle, D.B.; Matsuda, K. Probing new components (loop G and the $\alpha-\alpha$ interface) of neonicotinoid binding sites on nicotinic acetylcholine receptors. Pestic. Biochem. Physiol., 2015 121, 47-52.

[30] Tomizawa, M.; Yamamoto, I. Binding of nicotinoids and the related compounds to the insect nicotinic acetylcholine receptors. J. Pestic. Sci., 1992 17, 231-236.

[30] Bai, D.; Lummis, S.C.R.; Leicht, W.; Breer, H.; Sattelle, D.B. Actions of imidacloprid and a related nitromethylene on cholinergic receptors of an identified insect motor neurone. Pestic. Sci., 19933 197-204.

[31] Brown, L.A.; Ihara, M.; Buckingham, S.D.; Matsuda, K.; Sattelle, D.B. Neonicotinoid insecticides display partial and superagonist actions on native insect nicotinic acetylcholine receptors. J. Neurochem. 2006 99, 608-615.

[32] Ihara, M.; Matsuda, K.; Otake, M.; Kuwamura, M.; Shimomura, M. Komai, K. Akamatsu, M. Raymond, V. Sattelle D.B. Diverse actions of neonicotinoids on chicken alpha7, alpha4beta2 and Drosophila-chicken SADbeta2 and ALSbeta2 hybrid nicotinic acetylcholine receptors expressed in Xenopus laevis oocytes. Neuropharmacology 2003 45,133-44.

[33] Matsuda, K.; Kanaoka, S.; Akamatsu, M.; Sattelle, D.B. Diverse actions and target-site selectivity of neonicotinoids: structural insights. Mol. Pharmacol. 2009 76, 1-10.

[34] Ihara, M. Brown, L.A.; Ishida, C.; Okuda, H.; Sattelle, D B ; Matsuda, K. J. Actions of imidacloprid, clothianidin and related neonicotinoids on nicotinic acetylcholine receptors of American cockroach neurons and their relationship with insecticidal potency. Pestic. Sci. 2006 31, 35-40.

[35] Salgado, V.; Saar, R, Desensitizing and non-desensitizing subtypes of alpha-bungarotoxin-sensitive nicotinic acetylcholine receptors in cockroach neurons. J. Insect Phvsiol. 2004 50, 867-879.

[36] Casida, J.E.; Durkin, K.A. Neuroactive insecticides: targets, selectivity, resistance, and secondary effects. Annu. Rev. Entomol., 2013 58, 99117.

[37] Watson, G.B.; Loso, M.R.; Babcock, J.M.; Hasler, J.M.; Letherer, T.J.; Young, C.D.; Zhu, Y.; Casida, J.E.; Sparks, T.C. Novel nicotinic action of the sulfoximine insecticide sulfoxaflor Insect Biochem Mol. Biol., 2011 41, 432-439.

[38] Oliveira, E.E.; Schleicher, S.; Buchges, A,; Schmidt, J.; Kloppenburg, P.; Salgado, V.L. Desensitization of nicotinic acetylcholine receptors in central nervous system of the stick insect (Carausius morosus) by imidacloprid and sulfoximine insecticides. Insect Biochem. Mol. Biol., 2011 41, 872-880.

[39] Nauen, R.; Jeschke, P.; Velten, R.; Beck, M.E.; Ebbinghaus-Kintscher, U.; Thielert, W.; Wölfel, K.; Haas, M.; Kunz, K.; Raupach, G. 
Flupyradifurone: a brief profile of a new butenolide insecticide. Pest Manag. Sci., 2015 71, 850-862.

[40] Watson, G.B.; Chouinard, S.W.; Cook, K.R.; Geng, C.; Gifford, J.M.; Gustafson, G.D.; Hasler, J.M.; Larrinua, I.M.; Letherer, T.J.; Mitchell, J.C.; Pak, W.L.; Salgado, V.L.; Sparks, T.C.; Stilwell, G.E. A spinosyn-sensitive Drosophila melanogaster nicotinic acetylcholine receptor identified through chemically induced target site resistance, resistance gene identification, and heterologous expression. Insect. Biochem. Mol. Biol., 2010 40, 376384 .

[41] Perry, T.; McKenzie, J.A.; Batterham, P. A D $\alpha 6$ knockout strain of Drosophila melanogaster confers a high level of resistance to spinosad. Insect Biochem. Mol. Biol., 2007 37, 184-188.

[42] Grauso, M.; Reenan, R.A.; Culetto, E.; Sattelle, D.B. Novel putative nicotinic acetylcholine receptor subunit genes, D $\alpha 5, \mathrm{D} \alpha 6$ and $\mathrm{D} \alpha 7$, in Drosophila melanogaster identify a new and highly conserved target of adenosine deaminase acting on RNA - mediated A-to-I premRNA editing. Genetics, 2002 160, 1519-1533.

[43] Silva, W.M.; Berger, M.; Bass, C.; Williamson, M.; Moura, D.M. Ribeiro, L.M.; Siqueira, H.A. Mutation (G275E) of the nicotinic acetylcholine receptor $\alpha 6$ subunit is associated with high levels of resistance to spinosyns in Tuta absoluta (Meyrick) (Lepidoptera: Gelechiidae). Pestic. Biochem. Physiol., 2016 131, 1-8.

[44] Liu, Z. Williamson, M.S · Lansdell, S.J.; Han,Z · Denholm, I.; Millar, N.S. A nicotinic acetylcholine receptor mutation conferring targetsite resistance to imidacloprid in Nilaparvata lugens (brown planthopper). Proc. Natl. Acad. Sci. USA, 2005 102, 8420-8425.

[45] Bass, C.; Puinean, A.M.; Andrews, M.; Cutler, P,; Daniels, M.; Elias, J.; Paul, V.L.; Crossthwaite, A.J.; Denholm, I.; Field, L.M.; Foster, S.P.; Lind, R.; Williamson, M.S.; Slater, R. Mutation of a nicotinic acetylcholine receptor $\beta$ subunit is associated with resistance to neonicotinoid insecticides in the aphid Myzus persicae. BMC Neurosci., 2011 12, 51.

[46] Shimomura, M.; Yokota, M.; Ihara, M.; Akamatsu, M.; Sattelle, D.B.; Matsuda, K. Role in the selectivity of neonicotinoids of insectspecific basic residues in loop D of the nicotinic acetylcholine receptor agonist binding site.Mol Pharmacol 2006 70, 1255-1263

[47] Hallman, C.A.; Foppen, R.P.; van Turnhout, C.A.; de Kroon, H.; Jongejans, E. Declines in insectivorous birds are associated with high neonicotinoid concentrations. Nature 2014 511, 341-343.

[48] Cimino, A.M.; Boyles, A.B.; Thayer, K.A.; Perry M.J. Effects of neonicotinoid pesticide exposure on human health: a systematic review. Environ Health Perspect 2016, http://dx.doi.org/10.1289/EHP515

[49] Godfray, H.C.J.; Blacquie`re, T.; Field, L.M.; Hails, R.S.; Petrokofsky, G.; Potts, S.G.; Raine, N.E.; Vanbergen, A.J.; McLean, A.R. A restatement of the natural science evidence base concerning neonicotinoid insecticides and insect pollinators. Proc. R. Soc. Lond. B., $2014281,20140558$.
[50] Coulson, D. An overview of the environmental risks posed by neonicotinoid insecticides. J. Appl. Ecol., 2013 50, 977-987.

[51] Nagata, K.; Aistrup, G.L.; Song, J.H.; Narahashi, T. Subconductancestate currents generated by imidacloprid at the nicotinic acetylcholine receptor in PC 12 cells. Neuroreport 1996 10, 1025 1028

[52] Ihara, M.; Brown, L.A.; Ishida, C.; Okuda, H.; Sattelle, D.B.; Matsuda, $\mathrm{K}$. Actions of imidacloprid, clothianidin and related neonicotinoids on nicotinic acetylcholine receptors of American cockroach neurons and their relationships with insecticidal potency. J. Pestic. Sci. 2006 $31,35-40$.

[53] Tan, J.; Galligan, J.J.; Hollingworth, R.M. Agonist actions of neonicotinoids on nicotinic acetylcholine receptors expressed by cockroach neurons. Neurotoxicology 2007 28, 829-842.

[54] Matsuda, K.; Buckingham, S.D.; Freeman, J.C.; Squire, M.D.; Baylis, H.A.; Sattelle, D.B. Effects of the alpha subunit on imidacloprid sensitivity of recombinant nicotinic acetylcholine receptors. Br. J. Pharmacol. 1998 123, 518-524.

[55] Toshima, K.; Ihara, M.; Kanaoka, S.; Tarumoto, K.; Yamada, A.; Sattelle, D.B.; Matsuda, K. Potentiating and blocking actions of neonicotinoids on the response to acetylcholine of the neuronal $\alpha 4 \beta 2$ nicotinic acetylcholine receptor. J. Pestic. Sci. 2008 33, 146151

[56] Ihara, M.; Matsuda, K.; Shimomura, M.; Sattelle, D.B.; Komai K., Super agonist actions of clothianidin and related compounds on the SADB2 nicotinic acetylcholine receptor expressed in Xenopus laevis oocytes. Biosci. Biotechnol. Biochem. 2004 68, 761-763.

[57] Kagabu, S.; Matsuda, K.; Komai K. Preparation of dinotefuran related compounds and agonistic actions on $\operatorname{SAD} \beta 2$ hybrid nicotinic acetylcholine receptors expressed in Xenopus laevis oocytes. $J$. Pestic. Sci. 2002, 27, 374-377.

\footnotetext{
*Address correspondence to this author at the Centre for Respiratory Biology, UCL Respiratory, Division of Medicine, University College London, Rayne Building, 5 University Street London WC1E 6JF, UK; Tel
} +044-0203-1087749; E-mail: d.sattelle@ucl.ac.uk 